CASE REPORT

\title{
Failure of operative treatment in a fast bowler with bilateral spondylolysis
}

\author{
V S Ranawat, M B Heywood-Waddington
}

Br J Sports Med 2004;38:225-226. doi: 10.1136/bjsm.2002.003749

Modern day fast bowling places immense strain on the spine. Stress fractures of the lumbar region are common. If a period of conservative treatment fails to return a fast bowler to professional sport, surgery is considered. Good results have been reported using a direct screw repair of the spondylolytic defect. A case is presented of a failed surgical intervention with an alternative technique.

$\mathrm{T}$ he physical demands of the modern game of cricket is known to cause a variety of injuries. The professional era has resulted in most players being involved for the entire year, and this intensity places a huge strain on these sportsmen especially the fast bowlers.

The action of fast bowling places immense stresses on the spine, taking place as many as 300-600 times a week. ${ }^{1}$ The movements of hyperextension, lateral flexion, and thoracolumbar rotation in combination with a jerk force occurring when the fast bowler lands during his delivery stride are all major factors in the development of spondylolysis and spondylolisthesis. ${ }^{2}$ Stress fractures of the lumbar spine are common, and indeed the incidence of spondylolysis in a prospective group of young fast bowlers has been reported to be as high as $54 \%{ }^{3}$

We report a case of a failed operative procedure in a young fast bowler.

\section{CASE REPORT}

This case involved a very promising 19 year old fast bowler who developed bilateral L5 spondylolysis, diagnosed radiologically, after he had experienced an acute episode while playing for his county side. After three months of conservative treatment of rest and wearing of a corset, he was still unable to resume bowling and so it was decided that he would benefit from surgical intervention.

$\mathrm{He}$ underwent an L3/L4/L5/S1 fusion which involved posterior stabilisation of the lumbar spine with MeurigWilliams plates secured either side of the midline by screw fixation through the respective spinous processes. This procedure was performed outside our department at the end of that cricket season (September 1982). Postoperative recovery and rehabilitation were uneventful, and he returned to start the following season at full fitness without pain. However, during the early part of the season, he noticed swelling in the lumbar region, increasing in response to the exertion of bowling. Radiographs taken at this time showed that the lowermost screw had broken. It was decided to remove this screw as it was thought to be the cause of the swelling. Postoperative recovery was swift, and he again returned to full fitness. However, during this season he again noticed the lumbar swelling, but this did not impair his performance and he was selected to play at international level. Repeat radiographs showed that further screws had broken and the metalwork had become loose (fig 1). On examination at this stage there was a large fluctuant inflammatory swelling (some $25 \mathrm{~cm}$ in diameter), and this required regular drainage over the five days of his debut Test match. Microbiological assessment found no evidence of infection, and over 1 litre of fluid was aspirated. He was able to complete the Test match and the rest of the season although the swelling persisted.

At the end of the season he underwent further surgery to remove the remaining metalwork. At operation it was noted that the spondylolytic defects were stable and so no further intervention was undertaken. The player returned to open the bowling the following season and played successfully for eight further years at both international and county level without any further symptoms from his back. He eventually retired because of a knee injury.

\section{DISCUSSION}

At the time of this cricketer's injury, there was no documented knowledge on the treatment of stress fractures of the lumbar spine in fast bowlers. This case stimulated the senior author to review the condition, as he was heavily involved as orthopaedic advisor to the local county cricket club. Conclusions drawn were that the condition was present, with or without symptoms, in over $50 \%$ of fast bowlers. It probably developed before skeletal maturity during colt cricket when most players are allrounders. If conservative

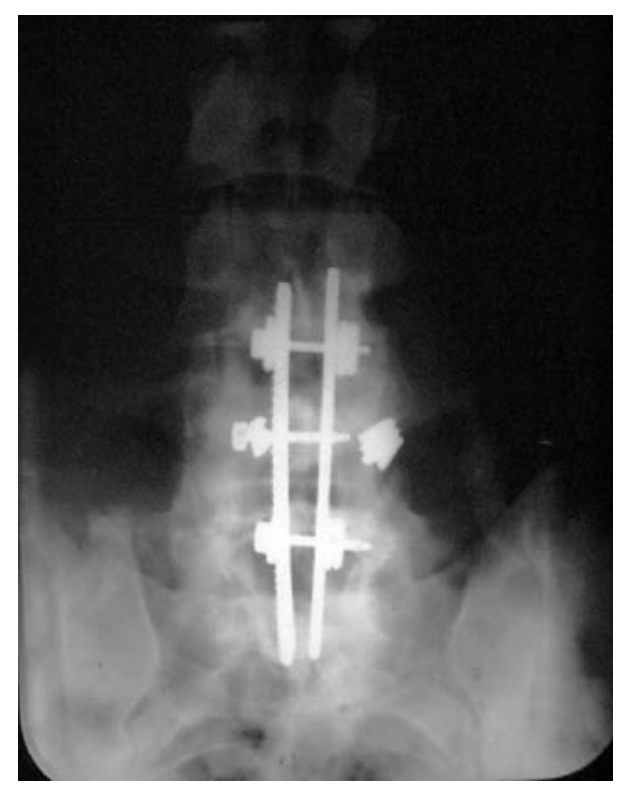

Figure 1 Radiograph of posterior lumbar fusion showing broken screws and loose metalwork. 


\section{Take home message}

Should conservative measures fail in the treatment of spondylolysis of the lumbar spine in the fast bowler, surgery can give good results. This case shows that posterior spinal stabilisation is a poor surgical option in this patient group.

methods of treatment were unsuccessful, direct repair of the defect seemed to be the most suitable surgical intervention.

This case shows that posterior stabilisation is a poor choice of operation for the young professional fast bowler. ${ }^{4}$ The failure of the metal appeared to be due to the repetitive stress of fast bowling. From our experience, ${ }^{2}$ we advocate initial treatment of this patient group by conservative means. This involves a period of complete rest until acute symptoms of back pain subside. This is followed by three months of a supervised graduated exercise regimen avoiding bowling. After this, a specialised bowling coach analyses the bowling action to assess whether the spine is being placed under any specific provocative stresses. A supervised reintroduction programme to bowling follows over the subsequent months. These conservative measures can be quite successful, and in our series has seen eight out of 18 professional cricketers return to full time sport. ${ }^{2}$ Should these conservative measures fail, Buck's repair (a localised screw fixation of the spondylolytic defect with bone grafting $)^{45}$ in combination with bowling action retraining where appropriate has enabled nine fast bowlers to continue their professional careers with an average follow up of over five years. ${ }^{2}$

\section{Authors' affiliations}

V S Ranawat, M B Heywood-Waddington, Broomfield Hospital, London, UK

Correspondence to: Mr Ranawat, Broomfield Hospital, RNOH SpR Rotation, 503 Liverpool Road, London N7 8NS, UK;

vijairanawat@hotmail.com

Accepted 8 July 2003

\section{REFERENCES}

1 Hardcastle P. Repair of spondylolysis in young fast bowlers. J Bone Joint Surg [Br] 1993;75:398-402.

2 Ranawat VS, Dowell JK, Heywood-Waddington MB. Stress fractures of the lumbar pars interarticularis in athletes: a review based on long term results in 18 professional cricketers. Injury 2003;34:915-19.

3 Hardcastle $\mathrm{P}$, Annear $\mathrm{P}$, Foster $\mathrm{DH}$, et al. Spinal abnormalities in young fast bowlers. J Bone Joint Surg [Br] 1992;74:421-5.

4 Buck JE. Direct repair of the defect in spondylolisthesis: preliminary report. $J$ Bone Joint Surg [Br] 1970;52:432-7.

5 Buck JE. Further thoughts on direct repair of the defect in spondylolisthesis. $J$ Bone Joint Surg [Br] 1979;61:123. 